REVISTA DO CENTRO DE CIÊNCIAS DA EDUCAÇÃO

Volume 39, n. 3 - p. 01-03, jul./set. 2021 - Florianópolis

\title{
A vacina como possibilidade de saída da pandemia
}

A pandemia da Covid-19 ainda é uma realidade no Brasil, mas esse trimestre nos dá a sensação de que seu fim pode estar próximo. Isso porque a oferta de diferentes tipos de vacinas fez acelerar o ritmo de vacinação no país a partir de junho (BRUM, 2021), alcançando, inclusive, o grupo de professores para sua $1^{\mathrm{a}}$ dose. Como consequência, setembro foi o mês com menos mortes pela doença em $2021 \mathrm{e}$ os números vêm decrescendo, apesar de ainda serem altos no Brasil. Apesar dos números favoráveis, os órgãos de saúde mantêm a orientação de uso de máscaras, higienização das mãos e distanciamento social, como medidas para a redução da Covid-19.

$\mathrm{Na}$ UFSC, as atividades administrativas e acadêmicas continuam em formato remoto, com a manutenção do distanciamento social para a segurança de todos. Estamos no final do primeiro semestre letivo de 2021 e a prudência e a ciência levam a Instituição a manter as atividades remotas por mais um semestre, a partir de outubro. O Colégio de Aplicação e o Núcleo de Desenvolvimento Infantil também mantêm suas atividades remotas, com constantes diagnósticos sobre 0 desenvolvimento das crianças e cientes da importância das atividades presenciais serem retomadas assim que possível.

$\mathrm{Na}$ educação básica, há uma grande diferença de abordagem entre as instituições públicas e particulares no que diz respeito ao retorno presencial das crianças ao espaço escolar. Por um lado temos as escolas particulares, com atividades presenciais desde o início de 2021, e por outro, as escolas públicas com aulas remotas em diferentes formatos. As consequências dessas diferenças serão cruciais nos próximos meses e anos e as investigações sobre estes temas ajudarão a compreender melhor quais ações serão mais efetivas em nosso futuro próximo. Esperamos receber em nossa revista muitos desses relatos, contribuindo assim para a difusão dos conhecimentos que esse momento histórico trará.

Dessa forma, compõem esse número 07 artigos do dossiê Educação, Direitos Humanos e Ética Hacker, organizado pelos professores Nelson de Luca Pretto, da Universidade Federal da Bahia (BA), Andrea Brandão Lapa e Marina Bazzo de Espíndola, ambas da Universidade Federal de Santa Catarina (UFSC), assim como 10 artigos de demanda contínua.

O primeiro artigo, $O$ Enem como política de avaliação e as contradições ao processo de democratização educacional, de Fabiane Maia Garcia, da Universidade Federal do Amazonas (UFAM), Rafaela Silva Marinho Caldas, da Secretaria Municipal de Educação (SEMED) e Gracimeire Castro Torres, da Universidade Federal do Amazonas (UFAM), discute a política de avaliação do Ensino Médio no Brasil a partir do Exame Nacional do Ensino Médio - ENEM e 
discute, também, os reflexos das mudanças trazidas pela reforma do Ensino Médio e da BNCC.

$\mathrm{O}$ artigo Fundamentalismo religioso \& educação: um enredo potencial à formação literária como direitos humanos, de Roselete Fagundes de Aviz, da Universidade Federal de Santa Catarina (UFSC), analisa relatos e histórias de vida de mulheres que sofreram algum tipo de violência quando criança, utilizando-se de plataformas digitais como ferramenta de coleta dos dados.

Ainda dentro do campo das narrativas, as investigadoras Carla de Oliveira Ferroni e Aline Sommerhalder, e o investigador Fernando Donizete Alves, todos da Universidade Federal de São Carlos (UFSCar), apresentam no terceiro artigo, intitulado Narrativas sobre brincar nas infâncias: contribuições para a formação de professores de infância, o estudo da história de vida de três professoras e duas estudantes do curso de Pedagogia e como o brincar nas infâncias afeta a sua constituição do ser professor.

O quarto artigo, intitulado Formação inicial de professores de pedagogia na região de fronteira, de Maria Elena Aquino Dutra, Maria Luzia da Silva Santana, ambas da Universidade Federal de Mato Grosso do Sul (UFMS), se propõe a jogar luz sobre a formação inicial de professores de Pedagogia em cidades gêmeas de cidades de fronteira, analisando as relações interculturais, além de buscar outras produções sobre o tema.

A gestão da educação é tema no quinto texto, Gestão da educação no estado da Bahia: o que revelam os documentos normativos do sistema estadual de educação (1990-2015), de Maciela Mikaelly Carneiro de Araújo e Solange Mary Moreira Santos, da Universidade Estadual de Feira de Santana, e de Selma Barros Daltro de Castro, da Universidade do Estado da Bahia, em que as autoras analisam diferentes concepções de gestão a partir de fontes documentais do Sistema Estadual de Educação do Estado da Bahia entre os anos de 1990 e 2015.

A perspectiva da gestão também é a fonte de estudo do sexto artigo, Ações cooperativas enatuadas na gestão, dos autores César Costa Machado, do Instituto Federal de Educação, Ciência e Tecnologia Sul-rio-grandense (IFSul), e Débora Pereira Laurino, da Universidade Federal do Rio Grande (FURG), que tenta compreender as ações cooperativas de professores gestores de um Instituto Federal de Educação. A pesquisa demonstrou o reflexo positivo da integração dos coletivos administrativos e pedagógicos nas decisões e na resolução de conflitos.

Maria Cristiane Lopes da Silva, da Secretaria da Educação do Estado do Ceará, e Rosemary de Oliveira Almeida, da Universidade Estadual do Ceará (UECE), apresentam o artigo Círculos de diálogo: a perspectiva das emoções com os professores, em que apresentam um olhar sobre o Círculo de Diálogo, um dos modelos da metodologia dos Círculos de Construção de Paz objetivando entender como os professores participantes, de escolas estaduais do Ceará, se sentem sob a perspectiva das emoções experienciadas.

Uma análise de experiências positivas como estudantes de ensino médio para a escolha profissional de futuros professores de física é tema do oitavo artigo, de Emanuel Cesar Pimentel, Cleci Teresinha Werner da Rosa, pesquisadores da Universidade de Passo Fundo (UPF). O texto Evidências do conhecimento metacognitivo na tomada de decisão por ser professor de física se propõe a 


\section{Editores Científicos}

Juliana Cristina Faggion Bergmann

David Antonio da Costa

Diana Carvalho de Carvalho

Eliane Santana Dias Debus

Patricia Laura Torriglia compreender se há evidências do conhecimento metacognitivo na tomada de decisão de atuar como professor, confrontando as experiências positivas em relação à física vivenciadas como aluno e a ativação do conhecimento metacognitivo.

Cristiana Garcez dos Santos Seixas e Luciana Esmeralda Ostetto, ambas da Universidade Federal Fluminense (UFF), discutem a proposta denominada "Estúdio do sensível" no texto: Espaço, arte e expressão na formação docente: iluminuras do sensível. Nele, as autoras analisam a adoção deste instrumento com um grupo de 8 professoras da Educação Infantil da rede pública, a partir de dados retirados de notas de campo, fotografias do processo e material narrativo-expressivo desenvolvido pelas professoras participantes.

Encerrando esse número, a expansão do ensino fundamental é o foco de interesse, com o texto de Gustavo Cunha de Araujo, da Universidade Federal do Tocantins (UFT), intitulado A educação no Brasil entre 1930 e 1985: priorizando a quantidade sobre a qualidade na expansão educacional. $O$ autor apresenta uma pesquisa qualitativa documental, baseando-se nas Leis de Diretrizes e Bases da Educação Nacional (LDB) dos anos de 1961 e de 1971.

\section{Referências}

BRUM, Gabriel Covid: com vacinação, setembro registra menor número de mortes em 2021. Radioagência Nacional. Publicado em 01/10/2021. Disponível em: https://agenciabrasil.ebc.com.br/radioagencia-nacional/saude/audio/2021-10/covid-comvacinacao-setembro-registra-menor-numero-de-mortes-em-2021. 